\title{
Antidepressants are an important part of treating depression
}

\author{
Jitender Sareen ${ }^{1,2,3,4 *}$ and Murray W. Enns ${ }^{1,2,3}$ \\ 1 Department of Psychiatry, University of Manitoba, Winnipeg, MB, Canada \\ 2 Department of Psychology, University of Manitoba, Winnipeg, MB, Canada \\ ${ }^{3}$ Department of Community Health Sciences, University of Manitoba, Winnipeg, MB, Canada \\ ${ }_{4}$ Canadian Psychiatric Association, Ottawa, ON, Canada \\ *Correspondence: sareen@cc.umanitoba.ca \\ Edited by: \\ Axel Cleeremans, Université Libre de Bruxelles, Belgium \\ Reviewed by: \\ Axel Cleeremans, Université Libre de Bruxelles, Belgium
}

\section{A commentary on}

Primum non nocere: an evolutionary analysis of whether antidepressants do more harm than good

by Andrews, P. W., Thomson, J. A. Jr, Amstadter, A., and Neale, M. C. (2012). Front. Psychology 3:117. doi: 10.3389/ fpsyg.2012.00117

A recent review paper, published online on April 242012 in Frontiers in Psychology, argues that antidepressants interfere with the normal homeostatic response of the body and cause more harm than good (Andrews et al., 2012). The authors cite a number of studies that show that antidepressants are associated with a range of side effects, that drug-placebo differences are small for mild to moderate depression, and that people on antidepressants may die prematurely.

Although we fully agree that the benefits of an intervention should outweigh the risks, the authors have presented a biased analysis of the literature. Their conclusion that antidepressants are more harmful than helpful is unwarranted. Media reporting of this biased conclusion could be harmful to patients struggling with depression who are trying to make difficult decisions related to treatment.

Depression is a mental illness that affects individuals of all ages, and across Canada. Rates of acute hospitalization for depression are consistently higher than for any other mental illness (Canadian Institute for Health Information, 2008). And as a predictor of early death, depression is on a par with smoking (Mykletun, 2009). Worldwide, depression is the leading cause of years lived with disability (Ustun et al., 2004). It can disrupt many aspects of life, such as maintaining employment and/or productivity in the workplace (Marcotte and Wilcox-Gok, 2001; Lerner et al., 2004; Virtanen et al., 2005). In fact, the negative impact of depression on job performance has been estimated to be greater than that of chronic conditions such as arthritis, hypertension, back problems, and diabetes (Wells et al., 1989; Kessler et al., 2001).

There are current standards on minimizing the bias of reviewing the literature (Stroup et al., 2000). However, the authors do not provide any information on how they selected the articles cited and only cite articles that support their argument.

Furthermore, a number of important studies that counter the authors' arguments are not included in their review. For example, ecological studies have shown that increases in the use of antidepressants are associated with lower rates of suicide (Olfson et al., 2003). A Manitoba study demonstrated that after the Health Canada warnings, the resulting reduction in the prescription of antidepressants was associated with an increase in youth suicides (Katz et al., 2008). A number of studies have demonstrated that the risk of suicide attempts is highest before the initiation of an antidepressant (Gibbons et al., 2005, 2007). A recent study by Gibbons et al. (2012) demonstrates that antidepressants decrease the rate of suicidal ideation and suicide attempts.

The authors of the review in Frontiers in Psychology argue that antidepressants interfere with the "natural homeostatic response." They even argue that treating a fever with Tylenol can interfere with the normal homeostatic response to the body. Although we can appreciate some aspects of their argument, there are many conditions where interference with the body's "natural" response is needed. Many physical illnesses such as diabetes, hypertension, cardiovascular disease, rheumatologic diseases, cancer and allergies are associated with abnormalities in natural responses to environmental triggers. Do the authors suggest that we should not treat these illnesses? Some highly toxic side-effects are expected with treatments of cancer and other serious physical illnesses. However, the patient and health care provider have to weigh the risks and benefits of the intervention with the disability and outcomes associated with illness. As we have argued above, the distress, disability, and mortality associated with depressive illness is enormous on both an individual and societal scale.

Yes, evidence based psychotherapies and antidepressants are equally effective. Antidepressant medication treatment should always be combined with psychotherapy. If available, psychotherapy should be considered as first line treatment for mild to moderate depression. However, evidence based psychotherapies are not necessarily readily available and there is a need to advocate for greater numbers of health care providers that can provide these therapies. It is worthy of note that a recent New England Journal of Medicine study, also not cited by the authors, demonstrated that collaborative care treatment of depression (including antidepressants and nurse provided therapy) improve both mental and physical health outcomes (Katon et al., 2010).

Finally, the argument that evidence from randomized control trials that show little difference between antidepressants and placebos proves that antidepressants are not effective is a simplistic interpretation of the data. Recent work has demonstrated that these trials show small mean differences between the two groups because they lump responders together with non-responders. 
When looking at subgroups of responders, there are large differences between antidepressants and placebo (Thase et al., 2011).

\section{REFERENCES}

Andrews, P. W., Thomson, J. A. Jr., Amstadter, A., and Neale, M. C. (2012). Primum non nocere: an evolutionary analysis of whether antidepressants do more harm than good. Front. Psychology 3:117. doi: 10.3389/fpsyg.2012.00117

Canadian Institute for Health Information. (2008). Hospital Mental Health Services in Canada, 2005-2006. Available at: http://www.cpa.ca/cpasite/userfiles/ Documents/Practice_Page/Hmhdb_annual_re port_2008_e.pdf

Gibbons, R. D., Brown, C. H., Hur, K., Davis, J. M., and Mann, J. J. (2012). Suicidal thoughts and behavior with antidepressant treatment: reanalysis of the randomized placebo-controlled studies of Fluoxetine and Venlafaxine. Arch. Gen. Psychiatry. PMID: 22309973. [Epub ahead of print].

Gibbons, R. D., Brown, C. H., Hur, K., Marcus, S. M., Bhaumik, D. K., and Mann, J. J. (2007). Relationship between antidepressants and suicide attempts: an analysis of the Veterans Health Administration data sets. Am. J. Psychiatry 164, 1044-1049.

Gibbons, R. D., Hur, K., Bhaumik, D. K., and Mann, J. J. (2005). The relationship between antidepressant medication use and rate of suicide. Arch. Gen. Psychiatry 62, 165-172.

Katon, W. J., Lin, E. H., Von Korff, M., Ciechanowski, P., Ludman, E. J., Young, B., Peterson, D., Rutter,
C. M., McGregor, M., and McCullough, D. (2010). Collaborative care for patients with depression and chronic illnesses. N. Engl. J. Med. 363, 2611-2620.

Katz, L. Y., Kozyrskyj, A. L., Prior, H., Enns, M. W., Cox, B. J., and Sareen, J. (2008). Effect of regulatory warnings on antidepressant prescription rates, use of health services and outcomes among children and adolescents. CMAJ 178, 1-7.

Kessler, R. C., Greenberg, P. E., Mickelson, K. D. Meneades, L. M., and Wang, P. S. (2001). The effects of chronic medical conditions on work loss and work cutback. J. Occup. Environ. Med. 43, 218-225.

Lerner, D., Adler, D. A., Chang, H., Lapitsky, L., Hood, M. Y., Permissinotto, C., Reed, J., McLaughlin, T. J., Berndt, E. R., and Rogers, W. H. (2004). Unemployment, job retention, and productivity loss among employees with depression. Psychiatr. Serv. 55, 1371-1378.

Marcotte, D. E., and Wilcox-Gok, V. (2001). Estimating the employment and earnings costs of mental illness: recent developments in the United States. Soc. Sci. Med. 53, 21-27.

Mykletun, A. (2009). Levels of anxiety and depression as predictors of mortality: the HUNT study. Br. J. Psychiatry 195, 118-125.

Olfson, M., Shaffer, D., Marcus, S. C., and Greenberg, T. (2003). Relationship between antidepressant medication treatment and suicide in adolescents. Arch. Gen. Psychiatry 60, 978-982.

Stroup, D. F., Berlin, J. A., Morton, S. C., Olkin, I., Williamson, G. D., Rennie, D, Moher, D., Becker, B. J., Stipe, T.A., and Thacker, S. B. (2000). Meta-analysis of observational studies in epidemiology: a proposal for reporting. JAMA 283, 2008-2012.
Thase, M. E., Larsen, K. G., and Kennedy, S. H. (2011). Assessing the true effect of active antidepressant therapy versus placebo in major depressive disorder: use of a mixture model. Br. J. Psychiatry 199, 501-507.

Ustun, T. B., Yuso-Mateos, J. L., Chatterji, S., Mathers, C., and Murray, C. J. L. (2004). Global burden of depressive disorders in the year 2000. Br. J. Psychiatry 184, 386-392.

Virtanen, M., Kivimaki, M., Elovainio, M., Vahtera, J., Kokko, K., and Pulkkinen, L. (2005). Mental health and hostility as predictors of temporary employment evidence from two prospective studies. Soc. Sci. Med. 61, 2084-2095.

Wells, K. B., Stewart, A., Hays, R. D., Burnam, M. A., Rogers, W., Daniels, M., Berry, S., Greenfield, S., and Ware, J. (1989). The functioning and well-being of depressed patients: results from the Medical Outcomes Study. JAMA 262, 914-919.

Received: 07 May 2012; accepted: 22 June 2012; published online: 20 July 2012

Citation: Sareen J and Enns MW (2012) Antidepressants are an important part of treating depression. Front. Psychology 3:240. doi: 10.3389/fpsyg.2012.00240

This article was submitted to Frontiers in Evolutionary Psychology, a specialty of Frontiers in Psychology.

Copyright $(\odot) 2012$ Sareen and Enns. This is an open-access article distributed under the terms of the Creative Commons Attribution License, which permits use, distribution and reproduction in other forums, provided the original authors and source are credited and subject to any copyright notices concerning any third-party graphics etc. 